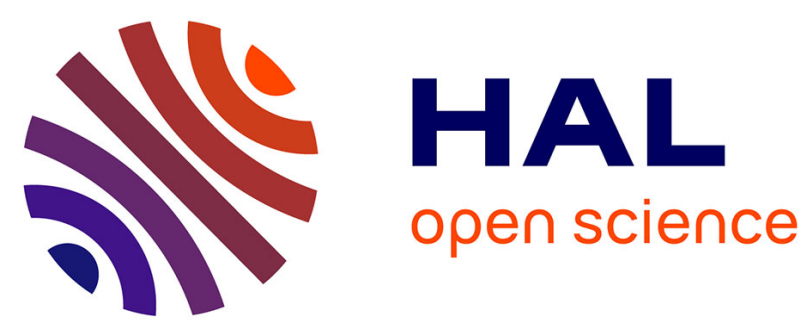

\title{
Performance Assessment of IR-UWB Body Area Network (BAN) based on IEEE 802.15.6 Standard
}

Huiliang Liu, Julien Sarrazin, Frédérique Deshours, Theodoros Mavridis, Luca Petrillo, Zewen Liu, Philippe de Doncker, Aziz Benlarbi-Delai

\section{- To cite this version:}

Huiliang Liu, Julien Sarrazin, Frédérique Deshours, Theodoros Mavridis, Luca Petrillo, et al.. Performance Assessment of IR-UWB Body Area Network (BAN) based on IEEE 802.15.6 Standard. Antennas and Propagation Society Newsletter, IEEE, 2016, 15, pp.1645 - 1648. 10.1109/LAWP.2016.2520021 . hal-01261310

\section{HAL Id: hal-01261310 https://hal.sorbonne-universite.fr/hal-01261310}

Submitted on 26 Jan 2016

HAL is a multi-disciplinary open access archive for the deposit and dissemination of scientific research documents, whether they are published or not. The documents may come from teaching and research institutions in France or abroad, or from public or private research centers.
L'archive ouverte pluridisciplinaire HAL, est destinée au dépôt et à la diffusion de documents scientifiques de niveau recherche, publiés ou non, émanant des établissements d'enseignement et de recherche français ou étrangers, des laboratoires publics ou privés. 


\title{
Performance Assessment of IR-UWB Body Area Network (BAN) based on IEEE 802.15.6 Standard
}

\author{
Huiliang Liu, Julien Sarrazin, Member, IEEE, Frédérique Deshours, Theodoros Mavridis, Student \\ Member, IEEE, Luca Petrillo, Zewen Liu, Philippe De Doncker, and Aziz Benlarbi-Delaï
}

\begin{abstract}
Performance of impulse radio-based ultra-wideband (IR-UWB) communications in wireless body area networks are investigated using the dedicated IEEE 802.15.6 standard. An IR-UWB transceiver system is implemented for both on-off keying and differential binary phase-shift keying modulations. Bit error rates are determined from measurements for different on-body links with different data rates. It is shown that that using a $25 \mathrm{~dB}$-gain LNA at the receiver, reaching an uncoded BER of $10^{-3}$ was not possible for some links operating at higher data rates. Power and energy consumption issues are then addressed and results in terms of required $\mathrm{pJ} / \mathrm{bit}$ to achieve a certain quality of communication are given and discussed.
\end{abstract}

Index Terms-Body area network, IEEE 802.15.6, impulse radio, ultra-wideband, energy consumption.

\section{INTRODUCTION}

$\mathrm{U}$ LTRA-WIDEBAND (UWB) technology can be used at a very low energy level for short-range, high data rate wireless communication. In recent years, an important UWB application is wireless body area network (WBAN), which consists in communications for healthcare, medical monitoring, and entertainment. To meet the requirements of WBAN, the architecture of IEEE 802.15.6 standard offers one common MAC layer with three PHY layers, including narrowband (NB) PHY, UWB PHY, and human body communication (HBC) PHY. In UWB PHY, the impulse radio ultra-wideband (IR-UWB) is a strong candidate for WBAN [1]. Thus, the performance of on-body IR-UWB communications based on the IEEE 802.15.6 PHY definition is investigated in this paper by means of uncoded bit error rate (BER). Furthermore, power and energy consumption issues are also addressed.

Section II describes the studied system model while section III shows measurement settings and results. Finally, section IV concludes the paper.

H. Liu and Z. Liu are with Tsinghua University, Beijing, China, (e-mail: liuh115@mails.tsinghua.edu.cn; liuzw@tsinghua.edu.cn).

T. Mavridis, L. Petrillo, and P. De Doncker are with OPERA Dpt. Wireless Communications Group, Université Libre de Bruxelles (ULB), B-1050 Brussels, Belgium (e-mail: \{tmavridi, lpetrillo, pdedonck\}@ulb.ac.be).

J. Sarrazin, F. Deshours, T. Mavridis, and A. Benlarbi-Delaï are with Sorbonne Universités, UPMC Univ Paris 06, UR2, L2E, F-75005, Paris, France (e-mail: \{julien.sarrazin, frederique.deshours, aziz.benlarbi_delai\}@umpc.fr.).

\section{SYSTEM MODEL}

Two operation modes are defined in the UWB part of IEEE 802.15.6 standard, the default mode and the high quality of service (QoS) mode. In the default mode, IR-UWB is defined as mandatory PHY with on-off keying (OOK) modulation. In the high QoS mode, IR-UWB is also mandatory with differential binary phase-shift keying (DBPSK) modulation. Thus, both OOK and DBPSK schemes are considered in this paper. One bit rate is defined as mandatory, namely $0.4875 \mathrm{Mbps}$. In addition to this bit rate, two higher bit rates, 1.95 Mbps and 7.8 Mbps, are implemented. One channel is defined as mandatory for the low band whose central frequency is $3993.6 \mathrm{MHz}$ with $499.2 \mathrm{MHz}$ bandwidth, which will be considered throughout the paper. This channel is compliant with indoor and outdoor regulation of most countries.

The system model is simulated with Matlab and then implemented in the test bench. The model includes transmitter and receiver communicating pairs. The overall scheme includes a transmitter sending bit sequences modulated with bursts of pulses and a receiver receiving the signal that has propagated through the channel. Real channels for different links on the human body are used in measurement.

\section{A. Transmitter for $O O K$ and DBPSK}

The OOK modulation strategy assigns $b$ information bits from an alphabet of size $M=2^{b}$ with a coded-pulse sequence of length $2 b$ from a code set alphabet of the same size [2]. The mandatory symbol mapper is set with $b=1$, which corresponds to $M=2$. Then the pulse shaping shall place a pulse waveform when the input bit is 1 . Thus, the transmitting signal is given by

$x(t)=\sum_{n=0}^{2 b-1} d_{n}^{m} W\left(t-n T_{\text {sym }} / 2-m b T_{\text {sym }}-h^{2 b m+n} T_{w}\right)$

where $d_{n}{ }^{m}$ is the $n^{\text {th }}$ codeword over the $m^{\text {th }}$ transmitting symbol, $T_{\text {sym }}$ is the symbol time, $h^{j}$ is a time hopping sequence and $w(t)$ is the pulse waveform with pulse duration $T_{w}$. The chirp pulse shape with $500 \mathrm{MHz}$ bandwidth is used.

The DPSK modulation is differentially encoded such that the transmitting symbols are given by

$c_{m}=c_{m-1} \exp \left(j \varphi_{m}\right)$

where $c_{m}$ represents the $m^{\text {th }}$ differentially encoded symbol, $m=0,1, \ldots, N-1$ and $c_{-1}=1$. Such symbol carries either one bit of information (DBPSK) or two bits of information (DQPSK). In this paper, only DBPSK is taken into 
consideration.

After the generation of DBPSK symbols, the pulse shaping shall place a pulse waveform according to the UWB symbol structure. Then the transmitting signal is given by

$$
x(t)=\sum_{m=0}^{N-1} c_{m} w\left(t-m T_{s y m}-h^{(m)} T_{w}\right)
$$

where $c_{m}$ is the $m$-th transmitting symbol and $h^{(m)}$ is a time hopping sequence. There is no mandatory pulse shape in this standard. During the study, both chirp and short pulses burst have been tested and found to give similar results. So only short pulse-based results are presented in the following.

\section{B. Description of Receivers}

The receiver for OOK modulation is based on energy detection (ED) and its decision variable is expressed as [4]

$$
w_{n}^{(m)}=\int_{q}^{g+T w} r(t)^{2} d t
$$

where $r(t)$ is the received waveform. $q$ corresponds to the start position of the $n^{\text {th }}$ codeword in the $m^{\text {th }}$ symbol which is equal to $n T_{s y m} / 2+m T_{s y m}+h^{2 m+n} T_{w}$. The decision on the $m^{\text {th }}$ received bit is based on the comparison between the decision variables $w^{(m)}$. During one symbol time duration, if the integrated energy in the first received time slot is larger than in the second working slot, the received bit is zero. Otherwise it is one.

The receiver for DBPSK modulation is based on cross correlation. The decision variable is the cross correlation value of two adjacent pulses. It uses the previous received pulse burst to check the phase change without using locally generated signal sequence as reference. The decision variable can be presented as

$$
v^{(m)}=\int_{p}^{p+T w} r_{m}(t) r_{m-1}(t) d t
$$

where $p$ corresponds the start position of the $m^{\text {th }}$ symbol which is equal to $m T_{s y m}+h^{(m)} T_{w}$. If the decision variable is larger than zero, the received bit is detected as zero, otherwise it is one.

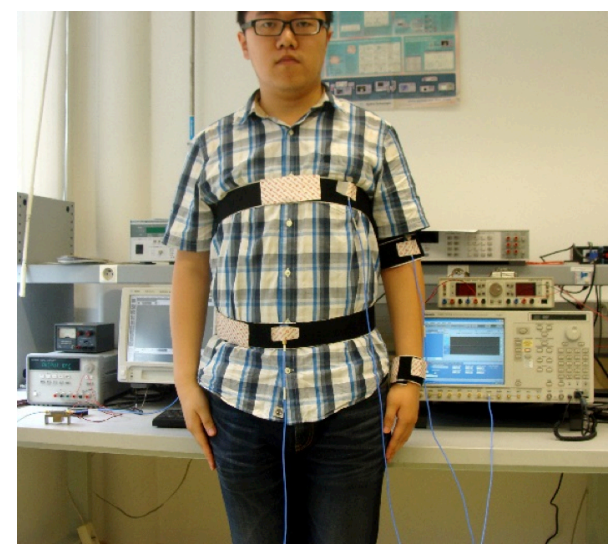

Fig. 1. On-body measurement experiment.

\section{Measurement}

\section{A. Measurement Setting}

To assess the performance of on-body communications in real indoor propagation environment, measurements are conducted in a $7.5 \mathrm{~m} \times 9.5 \mathrm{~m}$ laboratory room furnished with tables, chairs, computers, and other office equipment. The measurement system consists in an arbitrary waveform generator (Tektronix AWG7122B), a digital oscilloscope (Agilent DSO91204A), a low noise amplifier (LNA: Transcom TA010-180-30-15), and a control computer with Matlab.

The transmitted waveform is generated by Matlab and sent to the AWG. The AWG is used for waveform generation with a sampling rate of $12 \mathrm{GSa} / \mathrm{s}$ and an output power of $-18 \mathrm{dBm}$. Transmitting antennas are then fed with a 2-meter long coaxial cable. The transmitted signal has a $3.99 \mathrm{GHz}$ central carrier frequency.

The received signal at RX antenna position is amplified by the LNA connected to a $3 \mathrm{~dB}$ attenuator in order to provide a $25 \mathrm{~dB}$ gain at $4 \mathrm{GHz}$ with a noise figure worse than $6 \mathrm{~dB}$. Compared with available LNAs suitable for UWB BAN applications [3], this performance seems reasonable. The noise power at the receiver is about $-50.6 \mathrm{dBm}$ for the $500 \mathrm{MHz}$ channel. Then the amplified signal is directly sampled using the scope with a sampling rate of $12 \mathrm{GSa} / \mathrm{s}$ and sent to the computer. The signal stored in the computer is firstly filtered by an ideal $5^{\text {th }}$ order Chebyshev bandpass filter with $500 \mathrm{MHz}$ bandwidth and then synchronized by correlation with the original transmitted signal waveform. Finally receiver models are used to perform demodulation according to the considered modulation scheme (OOK or DBPSK). For each link, one measurement cycle tests $10^{5}$ bits and is repeated about 50 times. Results are then averaged in order to calculate the BER.

The body area network under study consists in a set of nodes, which is supposed to monitor health-related parameters, like heart rate, blood pressure, temperature, movements... To meet these application requirements, four nodes are deployed in chest, upper arm, wrist and knee with a hub on the waist [4]. Consequently, four links are investigated, between the waist and the other nodes. During the study, the subject under test stands up and remains in a relatively still position.

Wideband monopole antennas (Skycross SMT-3TO10M) are used for both transmission and reception. These antennas are quasi-omnidirectional with $3.1-10.6 \mathrm{GHz}$ bandwidth and about $0 \mathrm{dBi}$ gain at $4 \mathrm{GHz}$. They are directly attached on the body by a belt about $3-5 \mathrm{~mm}$ above the skin. The radiated polarization is consequently mainly tangential to the body. Although this polarization suffers from higher path-losses compared to the orthogonal one, this antenna orientation is the most practical from user's perspectives. The TX antenna is located at the waist whereas the RX antenna is successively located on the different node locations. Like in previous studies $[5,6]$, the interference from the cables was found to be negligible. A picture of the set-up is shown in Fig. 1 where TX and RX antenna locations are visible (except the knee location). The subject under test is an adult, male, whose height is 1.80 meters and weight is $81 \mathrm{~kg}$. 


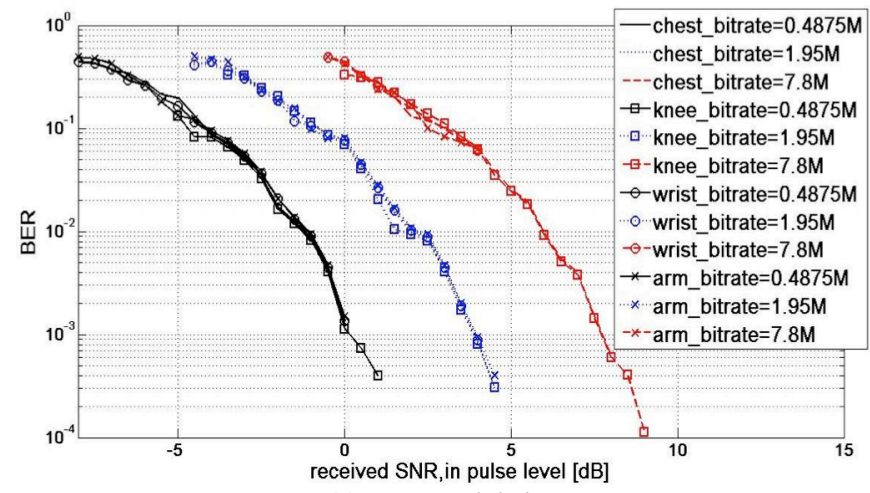

(a) OOK modulation

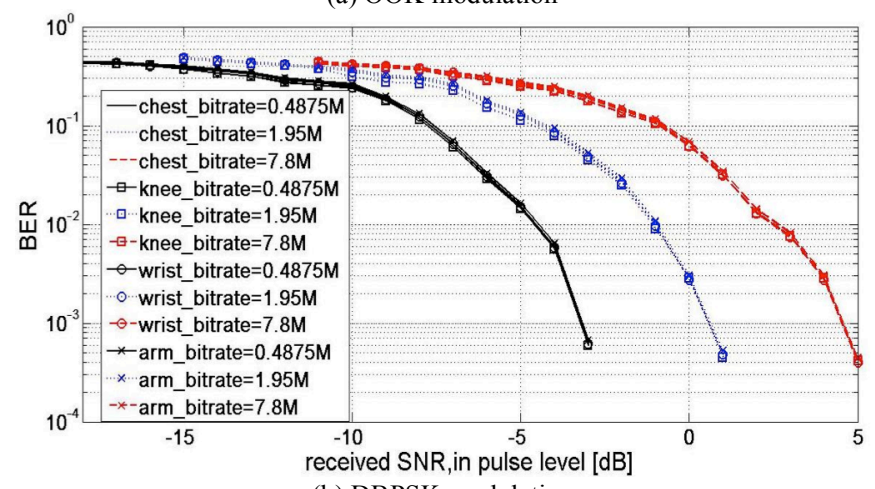

(b) DBPSK modulation

Fig. 2. Measurement performance: BER versus received SNR.

\section{B. Performance Analysis}

The performance of on-body communication is firstly evaluated in terms of uncoded BER versus received SNR in pulse level. Fig. 2a and Fig. 2b show measurement results for different links and bit rates for OOK and DBPSK modulation respectively. When comparing BER performances between OOK and DBPSK, it is noted that DBPSK outperforms OOK by approximately $3 \mathrm{~dB}$, which is consistent with theoretical calculation [7]. The lowest data rate is presented in black curve with circle marks. For the next blue curve with square marks and red curve with cross marks, the data rate is four times higher compared to the previous one, and this decreases by approximately $4 \mathrm{~dB}$ the performance in between each data rate.

The probability that the BER is less than $10^{-3}$ for different links and bit rates is investigated for different TX power values. TX power is varied using different combinations of attenuators at AWG's output. In that way, the full dynamic of generated signals is maintained. Results are shown in Fig. 3a for OOK modulation and in Fig. 3b for DBPSK. For each link, the lower bit rate needs lower transmitted power than higher bit rate to reach a given probability. It is therefore possible to use lower power consumption to realize a robust communication. The wrist link and arm link work worse because antennas are attached on the side of body and no direct propagation path exists (non light-of-sight conditions). The knee link has the best performance and outperforms the chest link which suffers slightly from belly shadowing. While comparing results from Fig. 3a and Fig. 3b, one has to take into account that because of the time duration required to

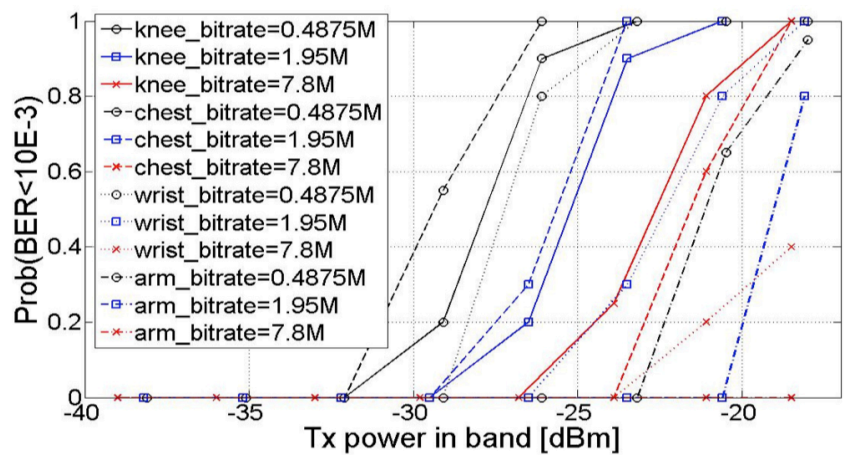

(a) OOK modulation

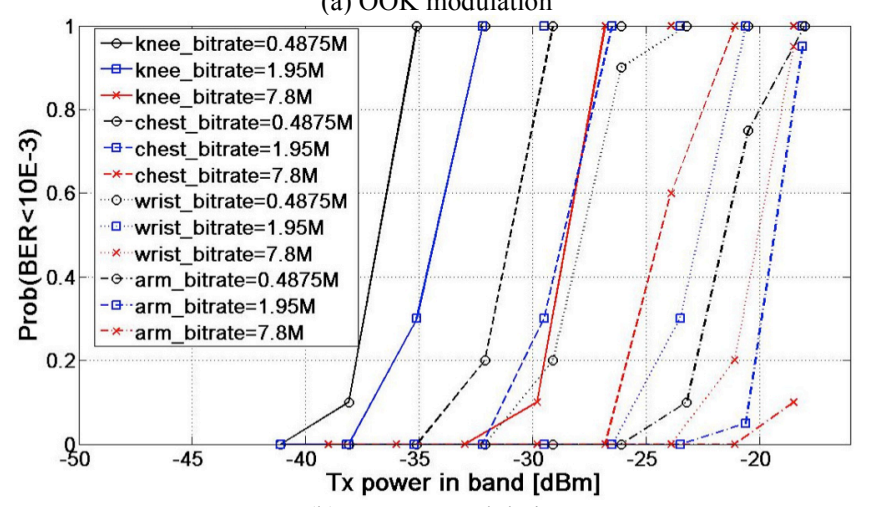

(b) DBPSK modulation

Fig. 3. Performance of detection capability for different links.

perform all the measurements, OOK and DBPSK performance have been measured over two consecutive days. Consequently, antenna positions and subject's body orientation could not be kept strictly unchanged. Indeed, knee and chest performances are more similar in the OOK scenario than in the DBPSK scenario. Slight changed in the antenna positions, which would have more or less emphasized the belly shadowing, could explain this. Due to the limitation of the AWG, the transmitted power in band can only reach $-18 \mathrm{dBm}$ whereas the regulation limit is $-15 \mathrm{dBm}$ for a $500 \mathrm{MHz}$ band. So there is a $3 \mathrm{~dB}$ room to improve these results, of course at the expense of higher power consumption. However, it is noticeable that achieving BER $<10^{-3}$ will be difficult for highest bit rates (considering a $25 \mathrm{~dB}$ gain LNA).

While it is clear from Fig. 3 that using lower bit rates leads to using lower TX power, it does not necessary mean lower energy consumption. The duty cycle to transmit a given data must also be taken into account. In BAN, each sensor having a limited battery size, energy aspects become a critical issue. The TX power should naturally be high enough to reach a given SNR but the energy consumption should be kept as low as possible at the same time. That is why the different bit rates are now investigated in terms of TX energy consumption. Taking into account performance of IR-UWB transmitters TABLE I

ENERGY PER BIT OF TX

\begin{tabular}{cccc}
\hline \hline $\begin{array}{c}\text { (OOK/DBP } \\
\text { SK) }\end{array}$ & $0.4875 \mathrm{Mbps}$ & $1.95 \mathrm{Mbps}$ & $7.8 \mathrm{Mbps}$ \\
\hline Chest link & $91.1 \mathrm{pJ} / 48.9 \mathrm{pJ}$ & $54.6 \mathrm{pJ} / 25.0 \mathrm{pJ}$ & $45.3 \mathrm{pJ} / 20.2 \mathrm{pJ}$ \\
Knee link & $114.8 \mathrm{pJ} / 12.8 \mathrm{pJ}$ & $57.2 \mathrm{pJ} / 6.43 \mathrm{pJ}$ & $40.4 \mathrm{pJ} / 5.70 \mathrm{pJ}$ \\
Wrist link & $162 \mathrm{pJ} / 128 \mathrm{pJ}$ & $169 \mathrm{pJ} / 101 \mathrm{pJ}$ & $\mathrm{NA} / 40.3 \mathrm{pJ}$ \\
Arm link & $776 \mathrm{pJ} / 691 \mathrm{pJ}$ & $\mathrm{NA} / 194 \mathrm{pJ}$ & $\mathrm{NA} / \mathrm{NA}$ \\
\hline
\end{tabular}


available in the literature [8]-[9], a total efficiency of $4 \%$ for the transmitter is considered.

Table I shows the minimum TX energy per bit required at the transmitter to reach a $90 \%$ probability that BER is less than $10^{-3}$. Results are given for the three investigated bit rates and for both modulation schemes. Although results are given for all links, it is to be noted that reaching $90 \%$ probability that BER $<10^{-3}$ was not possible for some bit rates for wrist and arm links in OOK scenarios, and for arm link in DBPSK scenarios. Overall, it can be observed that OOK modulation needs more energy than DBPSK to achieve the same performance. So from a transmitter point of view, DBPSK outperforms OOK. However, if both TX and RX were to be considered, conclusions could be different since DBPSK needs to sample received signals, which is energy consuming. Nevertheless, if the receiver is a central unit (presumed larger and more powerful, like smartphone-type), using DBPSK modulation could be an interesting option in order to keep node's complexity as low as possible while the receiver's digital processing is performed into the central unit. Table I also shows the great heterogeneity in the results. In fact, the lowest energy per bit is achieved at $5.70 \mathrm{pJ} / \mathrm{bit}$ for the knee link with the highest bit rate and DBPSK modulation whereas the highest energy is $776 \mathrm{pJ} / \mathrm{bit}$ with the lowest bit rate and OOK modulation. So a factor of 136 exists between these links. Consequently, designing a unique versatile solution for transmitters appears to be a non-easy task and an optimization depending on the type of link may have to be conducted.

\section{CONCLUSION}

In this paper, we have presented measurement results using a transceiver system following the IEEE 802.15.6 IR-UWB PHY definition with OOK and DBPSK modulations. Performance is compared for different links with different bit rates. For each link, lower bit rates need lower transmitted power than higher ones to reach a given BER value. However, higher bit rates remain more energy efficient even if it is more difficult to reach an acceptable probability for the BER to be less than $10^{-3}$ for instance. In fact, considering UWB density power regulation and specific propagation issues related to the human body (NLOS conditions, body absorption...), achieving robust on-body communications appears to be rather challenging. In particular, it has been shown that over $25 \mathrm{~dB}$ gain LNAs are required even for quasi-still positions of the human body. This fact consequently raises the issue of energy consumption in IR-UWB BANs for $\mathrm{mid} / \mathrm{long}$ term applications, especially if small sensors, with limited room for the battery, are considered. Furthermore, as perspectives of this study, additional experimentations are required in order to investigate the effect of the subject's mobility on the performance and on the energy consumption. Also, different subjects (male/female/child) with various morphologies (small, tall, etc.) need also to be considered in order to draw more global conclusions.

\section{ACKNOWLEDGMENT}

This work was performed within the Labex SMART supported by French state funds managed by the ANR within the Investissements d'Avenir programme under reference ANR-11-IDEX-0004-02.

\section{REFERENCES}

[1] IEEE Standard for local and metropolitan area networks - Part 15.6: Wireless Body Area Networks, IEEE Standard, 2012.

[2] M. Hernandez, R. Kohno, "UWB systems for body area networks in IEEE 802.15.6", IEEE International Conference on Ultra-Wideband (ICUWB), pp. 235-239, Sept. 2011

[3] S. Soldà, M. Caruso, A. Bevilacqua, A. Gerosa, D. Vogrig, A. Neviani, "A $5 \mathrm{Mb} / \mathrm{s}$ UWB-IR Transceiver Front-End for Wireless Sensor Networks in 0.13 um CMOS", IEEE Journal of Solid-State Circuits, vol. 46, no.7, pp. 1636-1647, July 2011.

[4] D.B. Smith, D. Miniutti, T.A. Lamahewa, L.W. Hanlen, "Propagation Models for Body-Area Networks: A Survey and New Outlook", IEEE Antennas and Propagation Magazine, vol. 55, no. 5, pp. 97-117, Oct. 2013

[5] L. Lingfeng, S. Van Roy, F. Quitin, P. De Doncker, C. Oestges, "Statistical characterization and modeling of Doppler spectrum in dynamic on-body channels", IEEE Antennas and Wireless Propagation Letters, vol. 12, pp. 186-189, 2013

[6] S. Van Roy, F. Quitin, L. Lingfeng, C. Oestges, F. Horlin, J.-M. Dricot, P. De Doncker, "Dynamic Channel Modeling for Multi-Sensor Body Area Networks", IEEE Transactions on Antennas and Propagation, vol. 61, no. 4, pp. 2200-2208, Apr. 2013

[7] M.-G. Di Benedetto, G. Giancola, "Performance Analysis for the UWB Radio Link", in Understanding Ultra Wide Band Radio Fundamentals, $1^{\text {st }}$ ed., New Jersey:Prentice Hall, pp. 230-258, 2004.

[8] M. Crepaldi, D. Dapra, A. Bonanno, I. Aulika, D. Demarchi, P. Civera, "A Very Low-Complexity $0.3-4.4 \quad \mathrm{GHz} \quad 0.004 \mathrm{~mm}$ All-Digital Ultra-Wide-Band Pulsed Transmitter for Energy Detection Receivers", IEEE Transactions on Circuits and Systems I: Regular Papers, vol. 59, no. 10 , pp. 2443 - 2455, Oct. 2012

[9] O.Z. Batur, E. Akdag, H.K. Akkurt, A. Oncu, M. Koca, G. Dundar, "An Ultra Low-Power Dual-Band IR-UWB Transmitter in 130-nm CMOS", IEEE Transactions on Circuits and Systems II: Express Briefs, pp. 701705 vol. 59, Issue: 11, Nov. 2012 